\author{
Е.А. Корниенкоㄹ, К.М. Комаров ${ }^{3}$, М.Ю. Типикина ${ }^{2}$, Т.Б. Лобода ${ }^{1}$ \\ ${ }^{1}$ Санкт-Петербургский государственный педиатрический медицинский университет, Российская Федерация \\ 2 Детская городская клиническая больница № 5 им. Н.Ф. Филатова, Санкт-Петербург, Российская Федерация \\ 3 Детская городская больница № 22, Санкт-Петербург, Российская Федерация
}

\title{
Применение осмотических
}

\section{слабительных в лечении хронических запоров у детей}

Контактная информация:

Корниенко Елена Александровна, доктор медицинских наук, профессор, заведующая кафедрой гастроэнтерологии ФПК и ПП Санкт-Петербургского государственного педиатрического медицинского университета

Адрес: 194100, Санкт-Петербург, ул. Литовская, д. 2, тел.: (812) 412-91-58, e-mail: elenkornienk@yandex.ru

Статья поступила: 28.09.2012 г., принята к печати: 05.10.2012 г.

Для оценки эффективности и безопасности осмотических слабительных полиэтиленгликоля с молекулярной массой 4000 кДа и лактулозы при хронических функциональных запорах у детей было проведено сравнительное исследование их эффективности у 80 человек в возрасте от 1 до 16 лет (46 детей принимали полиэтиленгликоль, 34 - лактулозу). Пациенты наблюдались на фоне лечения в течение 2 нед, проводилась клиническая и лабораторная оценка эффективности и безопасности терапии. На фоне лечения в обеих группах нормализация стула была достигнута в среднем на 3-и сут лечения, у большинства больных купированы боли и диспепсические расстройства. Произошла нормализация консистенции стула. Изменений электролитного состава крови не наблюдалось. Каких-либо побочных эффектов препаратов не отмечено, но в первые дни приема лактулозы достоверно чаще регистрировали флатуленцию и урчание в животе, которые проходили самостоятельно при продолжении лечения. Лактулоза и полиэтиленгликоль 4000 продемонстрировали эффективность и безопасность в лечении хронических функциональных запоров у детей и могут быть рекомендованы к применению, в Т. ч. у пациентов раннего возраста.

Ключевые слова: дети, запоры, лактулоза.

(Вопросы современной педиатрии. 2012; 11 (5): 152-155)

\section{ВВЕДЕНИЕ}

Запор - нарушение функционирования кишечника, выражающееся в увеличении интервалов между актами дефекации по сравнению с индивидуальной физиологической нормой или систематически недостаточным опорожнением кишечника.

В физиологических условиях частота дефекаций может варьировать в зависимости от характера питания, количества употребляемой жидкости и других обстоятельств. У детей первых месяцев жизни, находящихся на грудном вскармливании, частота стула может колебаться от 1 до 6-7 раз в день, при переходе на дефинитивное питание стул становится более густым и редким (табл. 1). Исходя из этих представлений, о запоре у детей в возрасте до 3 лет можно говорить при частоте стула реже 6 раз в нед. Грудное молоко усваивается лучше, чем детские адаптированные смеси: белок женского молока создает более нежный сгусток, быстрее эвакуируется и всасывается, жиры легче усваиваются, перевариваясь липазой желудка, и не формируют кальциевые мыла; галактоолигосахариды оказывают пребиотическое действие, способствуют образованию

\section{E.A. Kornienko ${ }^{1}$, K.M. Komarov ${ }^{3}$, M.J. Tipikina ${ }^{2}$, T.B. Loboda ${ }^{1}$}

${ }^{1}$ St. Petersburg State Pediatric Medical University, Russian Federation

2 N.F. Filatov Children Clinical Hospital № 5, St. Petersburg, Russian Federation

${ }^{3}$ Children Municipal Hospital № 22, St. Petersburg, Russian Federation

\section{Osmotic laxatives in treatment of chronic constipations in children}

A comparative trial including 80 patients at the age of 1-16 years old was performed in order to evaluate efficacy and safety of osmotic laxatives polyethylene glycol with molecular mass of $4000 \mathrm{kDa}$ and lactulose (46 children received polyethylene glycol, 34 - lactulose) in children with chronic functional constipations. The observation period during the treatment lasted for 2 weeks, clinical and laboratory evaluation of the therapy efficacy and safety was carried out. The normalization of stool was achieved on the average in 3 days of treatment in both groups, pain and dyspepsia were arrested in the majority of the patients. Stool consistency was normalized. No sideeffects were registered. However in the first days of lactulose treatment there were reliably more complaints on flatulence and rumbling, which passed spontaneously. Lactulose and polyethylene glycol were shown to be effective and safe in treatment of chronic functional constipations in children and can be recommended for usage even in infants.

Key words: children, constipations, lactulose.

(Voprosy sovremennoi pediatrii - Current Pediatrics. 2012; 11 (5): 152-155) 
Таблица 1. Нормальная частота дефекаций у детей разного возраста

\begin{tabular}{|l|c|c|}
\hline \multicolumn{1}{|c|}{ Возраст } & Частота стула & детей \\
\hline $1-4$ года & $1-2$ раза в день через день & $60-85$ \\
\hline $4-12$ лет & $4-9$ раз в нед & 95 \\
\hline
\end{tabular}

короткоцепочечных жирных кислот, которые, обладая осмотическим эффектом, послабляют стул. Поэтому стул у детей грудного возраста по консистенции и виду напоминает жидкую горчицу, имеет слабокислый запах и pH 5,5-6,5. Иногда у детей на грудном вскармливании могут случаться эпизоды более редкого стула вследствие почти полного усвоения пищевых ингредиентов, но при этом общее самочувствие ребенка не страдает, живот не увеличивается в размерах, консистенция стула остается мягкой, ребенок нормально прибавляет в весе. Если задержки становятся регулярными, а стул - твердым и отходит не в полном объеме, это следует расценивать как запоры. Очень важно обращать внимание на весовые прибавки, размеры живота, наличие беспокойства. Если нарушается хотя бы один из этих показателей, ребенку требуется углубленное обследование.

Стул при запорах обычно уплотнен, фрагментирован или напоминает овечий. Иногда плотными могут быть только первые порции, а последующие имеют нормальную или даже мягкую консистенцию. Дефекация может быть частичной, малыми порциями. После периода запора стул периодически отходит в большом объеме, может быть даже разжижен. Запор может сопровождаться беспокойством ребенка, болями в животе, которые исчезают или облегчаются после дефекации. При упорных запорах может увеличиваться живот, при пальпации иногда обнаруживают плотные каловые массы в нижнем левом квадранте.

Популяционные исследования, проведенные в Европе и Азии, показали, что запоры имеются у 10-20\% людей $[1,2]$. Жалобы на запоры предъявляют примерно $3 \%$ детей на приеме у педиатра и 10-25\% на приеме у детского гастроэнтеролога [3]. Запоры считаются функциональными, если отсутствуют анатомические причины их возникновения. Они также могут быть вторичными на фоне повреждений спинного мозга, системных и эндокринных заболеваний, приема медикаментов. Только у $10 \%$ детей запоры связаны с органической патологией, в 90\% случаев они имеют функциональный характер.

Механизмы, лежащие в основе функциональных запоров, весьма многообразны. Они могут заключаться В нарушении функции толстой кишки, прямой кишки, анальных сфинктеров, регулирующего влияния медиаторов нервной системы кишечника и, наконец, бывают результатом произвольной задержки стула. у 90\% детей не удается обнаружить какую-либо очевидную причину запоров. В числе наиболее частых причин называют изменения диеты, систематическое подавление позыва на дефекацию, стресс, перенесенные кишечные инфекции. Систематическая задержка стула приводит к накоплению каловых масс, перерастяжению ампулы прямой кишки и снижению чувствительности ее рецепторного аппарата. Вне зависимости от причины запоры имеют склонность к прогрессированию. До настоящего времени остается неясным, что первично: снижение чувствительности рецепторов или накопление каловых масс. Однако в любом случае создается некий порочный круг, который приводит к усилению патологического состояния. В итоге увеличивается время кишечного транзита. Избыточное накопление каловых масс в кишечнике само по себе снижает его моторику, приводит к изменению кишечного биоценоза и накоплению кишечных метаболитов [4]. Согласно клиническим наблюдениям, с лечением хронических запоров не следует затягивать, поскольку снижение чувствительности рецепторного аппарата, нарастающее по мере прогрессирования запоров, в запущенных стадиях может плохо поддаваться традиционной терапии.

Лечение функциональных запоров следует начинать с соблюдения диетических рекомендаций. Как правило, детям на грудном вскармливании не требуется дополнительной коррекции: прикормы следует вводить с 4 мес, предпочтение отдают овощным и фруктовым блюдам. Детям, находящимся на искусственном вскармливании, можно рекомендовать кисломолочные адаптированные смеси с пробиотиками ("НАН кисломолочный", "НАН комфорт»), смеси с фрукто- и галактоолигосахаридами ("Нутрилон Комфорт») или смесь с лактулозой ("Бифидус").

С полутора лет рекомендуют сажать детей на горшок 2-3 раза в день после еды на 5 мин для так называемого "туалетного тренинга".

При неэффективности коррекции диеты лечение проводят посредством назначения слабительных препаратов.

Из всей группы данных средств в детской практике рекомендованы осмотические слабительные. Основным механизмом их действия является размягчение стула за счет удержания воды, что облегчает транспортировку и делает дефекацию менее болезненной. При этом увеличивается объем стула, стимулируется моторика кишки, что также нормализует транзит. Действие лактулозы связано с предварительной бактериальной ферментацией с образованием осмотически активных метаболитов, прежде всего короткоцепочечных жирных кислот. Одновременно образуется газ (водород), поэтому на фоне приема лактулозы, особенно в первые дни, возможны метеоризм, флатуленция и урчание в животе [5]. В последние годы для лечения запоров с успехом используют полиэтиленгликоль [6]. Это инертный полимер с молекулярной массой 3200-4000 кДа. Он не всасывается в кишечнике и экскретируется в неизмененном виде с калом. Высокое осмотическое давление, которое создает полиэтиленгликоль, препятствует всасыванию воды, в результате чего каловые массы становятся более мягкими и объемными.

Цель исследования: сравнить клиническую эффективность полиэтиленгликоля (макрогола) с молекулярной массой 4000 кДа и лактулозы у детей с хроническими функциональными запорами.

\section{ПАЦИЕНТЫ И МЕТОДЫ}

\section{Участники исследования}

Исследование проводили на базе 2 детских стационаров г. Санкт-Петербурга: гастроэнтерологического отделения ДГКБ № 5 им. Н.Ф. Филатова и отделения 
колопроктологии ДГБ № 22. В него были включены 80 детей в возрасте от 1 до 16 лет с хроническими функциональными запорами. Все пациенты были разделены на 2 группы: в 1-ю вошли 46 детей, которым с лечебной целью был назначен полиэтиленгликоль (макрогол) 4000, во 2-ю - 34 ребенка с аналогичной патологией, которым назначили лактулозу. Дозу препаратов подбирали индивидуально в соответствии с возрастом. Стартовая доза полиэтиленгликоля составила 4-10 мг в сут в зависимости от возраста: детям до 4 лет давали 1 пакетик для детей (4 мг), детям от 4 до 8 лет - 2 пакетика (8 мг), детям старше 8 лет - 1 пакетик для взрослых (10 мг). Пациенты принимали препарат утром, до или во время еды, разводя в 50-100 мл воды. Стартовая доза лактулозы составила 6,7 г (10 мл), при отсутствии эффекта дозу увеличивали в 2 раза. Препарат также давали однократно утром. Курс лечения составил 2 нед. В течение этого времени проводился ежедневный опрос детей, осмотр, а также оценка характера и частоты стула.

\section{Методы исследования}

Диагноз устанавливали на основании жалоб пациентов и их родителей на регулярные запоры продолжительностью более 3 мес. У 67 детей с упорными запорами было проведено рентгенологическое исследование (ирригография) с целью исключения органической патологии (болезни Гиршпрунга, нарушений фиксации кишки). Детей с верифицированной органической патологией в исследование не включали. 42 пациентам была проведена фибросигмоскопия (или колоноскопия) для исключения воспалительных заболеваний толстой кишки. У 23 детей обнаружили слабые признаки катарального проктосигмоидита, которые не имели специфического характера и рассматривались как проявления синдрома раздраженного кишечника.

Перед началом лечения и спустя 2 нед от старта терапии произведено исследование содержания электролитов (натрий, калий, хлор, бикарбонат, кальций) крови и оценка массы тела. Результаты сравнивали как между группами, так и внутри каждой группы по ходу лечения.

\section{Статистическая обработка данных}

Статистический анализ результатов выполняли с использованием критерия Вилкоксона. Оценивали медиану и доверительный интервал (ДИ), для качественных параметров рассчитывали $\chi^{2}$-критерий. Различия считали достоверными при $p<0,05$.

\section{РЕЗУЛЬТАТЫ}

Средний возраст детей 1-й группы составил 8,2 (ДИ 6,0-10,4) года, 2-й группы - 7,6 (ДИ 5,8-9,7) года. В обеих группах преобладали девочки: $58 \%$ в 1-й и $56 \%$ во 2-й группе. Дети имели средние параметры физического развития, дефицит массы I степени отмечен у $18 \%$ больных 1-й и 22\% пациентов 2-й группы. Из сопутствующих заболеваний у детей 1-й группы в 65\% случаев была установлена хроническая гастродуоденальная патология (хронический гастродуоденит), в 24\% - дискинезии желчевыводящих путей, в 12\% - лямблиоз. У обследуемых 2-й группы хронический гастродуоденит был обнаружен в 56\%, дискинезии желчевыводящих путей - в 20\%, лямблиоз - в 14\% случаев. Лечение этих сопутствующих заболеваний было проведено ранее и не совпало по времени с приемом слабительных препаратов. Других медикаментов, влияющих на кишечный транзит и консистенцию кала, дети не получали. Очистительные клизмы перед началом лечения назначали при тяжелых запорах курсом на 3 дня.

Исходные клинические симптомы представлены в табл. 2. Достоверных отличий между двумя группами по симптоматике не установлено. Основными жалобами пациентов были: редкий стул - в среднем 3 (ДИ 2,4-3,3) раза в нед в 1-й группе и 4 (ДИ 3,1-5) во 2-й; боли в животе - у $67 \%$ детей 1-й группы и 76\% пациентов 2-й, которые обычно уменьшались или исчезали после дефекации. Менее часто отмечали метеоризм (у 50 и 53\%, соответственно), флатуленцию (27 и 26\%, соответственно), очень редко тошноту (6\% в обеих группах).

Характер стула у большинства пациентов обеих групп (92\%) при оценке по Бристольской шкале соответствовал

Таблица 2. Клинические симптомы до и после приема слабительных

\begin{tabular}{|c|c|c|c|c|}
\hline \multirow{2}{*}{ Симптомы } & \multicolumn{2}{|c|}{ 1-я группа $(n=46)$} & \multicolumn{2}{|c|}{ 2-я группа $(n=34)$} \\
\hline & Исходно & После лечения & Исходно & После лечения \\
\hline Боли в животе & $32(67 \%)$ & $12(25 \%)$ & $26(76 \%)$ & $11(32 \%)$ \\
\hline Метеоризм & $24(50 \%)$ & $5(10 \%)$ & $18(53 \%)$ & $11(32 \%)$ \\
\hline Флатуленция & $13(27 \%)$ & $6(12,5 \%)$ & 9 (26\%) & $21(62 \%)$ \\
\hline Тошнота & $3(6 \%)$ & $1(2 \%)$ & $2(5,8 \%)$ & 0 \\
\hline Рвота & $1(2 \%)$ & 0 & $1(2,9 \%)$ & 0 \\
\hline Плохой аппетит & $18(37,5 \%)$ & $10(21 \%)$ & $14(29 \%)$ & $12(25 \%)$ \\
\hline Частота стула (раз в нед) & 3 (Ди 2,4-3,3) & 7 (ДИ 5-8) & 4 (Ди 3,1-5) & 6 (Ди 4-7) \\
\hline $\begin{array}{l}\text { Характер стула: } \\
\text { Твердый } \\
\text { Нормальный } \\
\text { Жидкий }\end{array}$ & $\begin{array}{c}44(92 \%) \\
4(8 \%) \\
0\end{array}$ & $\begin{array}{c}5(10 \%) \\
41(85 \%) \\
2(5 \%)\end{array}$ & $\begin{array}{c}31(92 \%) \\
3(8 \%) \\
0\end{array}$ & $\begin{array}{c}3(8 \%) \\
31(92 \%) \\
1(3 \%)\end{array}$ \\
\hline Увеличение дозы препаратов & 0 & $12(25 \%)$ & 0 & $12(35 \%)$ \\
\hline Использование клизм или других слабительных & 0 & $2(5 \%)$ & 0 & $10(29 \%)$ \\
\hline
\end{tabular}

Примечание. Жирным шрифтом выделены достоверно различающиеся показатели $(p<0,05)$. ДИ - доверительный интервал. 
1-му и 2-му типу, т.е. был твердым и свидетельствовал о замедлении кишечного транзита.

Назначение слабительных препаратов оказалось эффективным у большинства больных. Появление стула после назначения полиэтиленгликоля наблюдалось обычно на 2-3-й (ДИ 1-2,8) день, после назначения лактулозы - на 3-й (ДИ 2-4) день. Первоначальная доза оказалась достаточной для 36 (75\%) детей 1-й группы и 24 (65\%) пациентов 2-й группы. 12 детям 1-й группы в связи с недостаточной эффективностью первоначальной дозы полиэтиленгликоля она была увеличена до 12 мг в день, что позволило достичь нормализации стула у 46 (95\%) больных. Только 2 пациентам были дополнительно назначены клизмы. Во 2-й группе в связи с недостаточной эффективностью стартовой дозы лактулозы у 12 (35\%) детей доза была увеличена до 20 мл в день.

Частота стула в 1-й группе на фоне приема полиэтиленгликоля составила в среднем 7 (ДИ 5-8) раз в нед, во 2-й группе (на фоне приема лактулозы) 6 (ДИ 4-7) раз в нед, т.е. хорошие результаты были достигнуты в обеих группах и достоверно не отличались друг от друга ( $p>0,05)$. у 41 (85\%) пациента 1-й группы нормализовались не только частота, но и характер стула: при оценке по Бристольской шкале он соответствовал 3-4-му типу. Во 2-й группе нормализация характера стула была достигнута у 31 (92\%) пациента, различия В характере стула и необходимости интенсификации терапии оказались недостоверными ( $p>0,05)$. У большинства детей обеих групп (42 и 44\%, соответственно) на фоне приема слабительных прошли боли в животе, улучшился аппетит (15\%), уменьшилась степень выраженности диспепсических явлений, в частности метеоризм (на $40 \%$ в 1-й группе и на $21 \%$ во 2-й), исчезла тошнота.

Переносимость обоих слабительных препаратов была хорошей. Никто из пациентов не потерял в весе. У всех детей как до, так и после лечения зарегистрированы нормальные показатели электролитов (натрия, калия, хлора, кальция) в крови. Все дети отмечали хорошие органолептические качества обоих препаратов. У 12 (25\%) пациентов 2-й группы на фоне приема лактулозы наблюдали небольшую флатуленцию и урчание в животе, особенно в первые 3 дня приема препарата. Через 5-7 дней эти явления смягчались или проходили.

\section{СПИСОК ЛИТЕРАТУРЫ}

1. Talley N. Y., Jones M., Nuyts G., Dubois D. Risk factors for chronic constipation based on a general practice sample. Am. J. Gastroentrol. 2003; 98: 1107-1111.

2. Cheng C., Chan A. O., Hui W.M., Lam S.K. Coping strategies, illness perception, anxiety and depression of patients with idiopatic constipation: a population-based study. Aliment. Pharmacol. Ther. 2003; 18: 319-326.

3. Loening-Baucke V. Chronic constipation in children. Gastroenterology. 1993; 105: 1557-1564.

4. Di Lorenzo C., Flores A. F., Reddy S. N., Hyman P. E. Use of colonic manometry to differentiate causes of intractable constipation in children. J. Pediatr. 1992; 120: 690-695.

5. Xing J.H., Soffer E.E. Adverse effects of laxatives. Dis. Colon. Rectum. 2001; 44: 1201-1209.

6. Di Palma J.A., De Ridder P.H., Orlando R. C. A randomized placebo controlled multicentre study of the safety and efficacy of a new polyethylene glycol laxative. Am. J. Gastroenterol. 2000; 95: 446-450.

\section{ЗАКЛЮЧЕНИЕ}

Исследование продемонстрировало эффективность осмотических слабительных препаратов у детей с функциональными хроническими запорами. Прием лекарственных средств данной группы приводил к быстрому достижению результата, стул нормализовался уже на 2-3-й день, длительный прием препарата не сопровождался какими-либо побочными явлениями. Особенно важно, что прием лактулозы (Дюфалак, производство компании Эбботт) и полиэтиленгликоля с молекулярным весом 4000 кДа не вызывал никаких изменений электролитного баланса, т.е. их назначение в детском возрасте оказалось абсолютно безопасным. Полученные нами данные согласуются с результатами Европейского исследования, проведенного в 2005 г. С. Dupont и соавт. [7, 8]. Безопасность длительного приема осмотических слабительных без дополнительного приема солей была доказана у взрослых [9], у которых лечение в течение 36 мес не сопровождалось изменением электролитного состава крови, снижением концентрации железа, фолатов, витаминов $B_{12}$ и D, не сопровождалось снижением интенсивности всасывания $D$-ксилозы, стеато- или креатореей. В педиатрической практике также была показана безопасность их приема на протяжении 3 лет [10]. Для детей в возрасте до 6 мес Дюфалак является единственным разрешенным с рождения слабительным препаратом. Основной механизм его действия - размягчение стула за счет удержания воды, что облегчает транспортировку и делает дефекацию менее болезненной. Если первоначальная доза препарата недостаточна, ее увеличивают в 2-3 раза. В первые дни приема возможны флатуленция и урчание в животе, которые впоследствии самостоятельно проходят. Механизм действия латкулозы сочетает пребиотическое и послабляющее влияние. В процессе бактериального брожения образуются короткоцепочечные жирные кислоты, обладающие энергетическим и осмотическим действием, снижается рН химуса и выработка токсичных азотистых соединений и аммиака. Курс лечения лактулозой не ограничен, его проводят в течение нескольких месяцев до достижения стойкого эффекта. Эффективность лечения запоров у детей зависит от своевременности его начала: если терапия начата в течение первых 2 лет после появления симптомов, она, как правило, приводит к хорошим результатам.

7. Dupont C., Ammar F., Leluyer B., Mathiex-Fortunet H., Garnier P. Polyethylene glycol (PEG) in constipating children: a dose determination study. Gastroenterology. 2000; 18 (2): 846.

8. Dupont C., Leluyer B., Maamri N., Morali A. Double-blind randomized evaluation of clinical and biological tolerance of polyethylene glycol in constipated children. J. Pediatr. Gastroenterol. Nutr. 2005; 41: 625-633.

9. Carraziari E., Badiali D., Bazzocchi G. Long term efficacy, safety and tolerability of low doses of isosmotic polyethylene glycol electrolyte balanced solution in the treatment of functional chronic constipation. Gut. 2000; 46: 522-526.

10. Autret E., Vasmant D. Determination of drug posology in pediatrics. Therapie. 1995; 50: 381-386.

11. Attar A., Lemann M., Ferguson A. Comparison of a low dose polyethylene glycol electrolyte solution with lactulose for treatment of chronic constipation. Gut. 1999; 44: 226-230. 